\title{
MENTAL, BEHAVIOPRAL AND PHYSICAL EFFECTS OF POWER ENHANCING DRUGS IN CHRONIC USERS
}

\author{
Faizan Mirza, ${ }^{1} \&$ Sadaf Ahmed ${ }^{1 \& 2}$ \\ 1. Neurovascular Physiology \& Biophysics Unit, Department of Physiology, University of Karachi \\ 2. Psychophysiology Research Division, Advance Educational Institute \& Research Centre \\ Corresponding author: fm.faizan.mirza@ gmail.com
}

\begin{abstract}
Exercising in gym is largely aimed at getting a desirably muscled physique that is subject to peer approval as well as associated with a higher self-esteem. Many people opt for workouts that define the lean body mass, whereas others aim at getting a beefed up body. The latter being a long and tiring process, pushes many people to opt for power enhancing drugs, for boosting their athletic endurance. Among others; steroids, erythropoietin, creatine, protein supplements are available over the counter all over Pakistani Pharmacies. Together with increasing the muscle bulk, they exert highly undesirable effects on hematological as well as lipid parameters. The present study evaluated and compared the side effects reported by the users of such PED on their mind, personality and body. A proforma was filled by each subject. The results showed that depending on the type of PED used, it has altered the personality of the individual significantly. Attributes that their personality and body did not have initially were observed by them upon chronic usage of these ergogenic aids. This lead us to conclude that "amount in PRs" is not the only price these PED users pay for attaining their desired beefed up physique, with which emerged another question, is that cost actually worth it?!!

KEYWORDS Exercise, Power enhancing Drug, Gym, workout, Personality
\end{abstract}

\section{INTRODUCTION}

Positive influence of exercise on psychological and physiological attributes has been agreed upon by several scientists (SIME, 1987). Strenuous exercise affects mood of the individual right away (Veale, 1987). Physical activity is linked with raised level of endorphins in brain (Colt , 1981). Here has been evidence that endogenous opioids in frontolimbic region of brain increases upon regular physical activity which can be linked with the euphoric state that the individuals feels as runners high (Henning, 2008). The present study focuses on individuals who workout in gym and use Power enhancing drugs (PED) such as steroids, creatine, protein, erythropoietin that are easily available over the counter in our country. These aid athletes to help in their performance on field and among non-athletes they result in better shaped body (Koch, 2002). Such PED are the favorite choice of youth in here to boost up their performance in gym, that quite soon gets translated into a wellmuscled physique. PED usage is reported to be causing an increased rage of anger as well as frustration (Mirza, 2013).

\section{OBJECTIVES OF THE STUDY}

To evaluate and compare various side effects observed by individuals exercising and using different PEDs.

\section{MATERIALS \& METHODS}

The study was conducted on 75 healthy male subjects, in the age group of 19-31, bearing weight in the range of $61 \mathrm{~kg}$ to $138 \mathrm{~kg}$ and height in the range of $5 \mathrm{ft}$ 6inches to $6 \mathrm{ft} 3$ inches, who have been doing regular exercise in a gym for last four to nine consecutive years and have been using PEDs for at least three years. They were asked to fill a proforma that aimed at analyzing the side effects that they started experiencing since they started abusing PED.

They were divided in following groups

S; 10 steroid users

SE; 6 steroids+EPO users

SC 8 steroids+creatine users

C; 7 creatine users

CZ;13 creatine+zinc users

P; 19 protein users

PZ 12 protein+zinc users

\section{RESULTS \& DISCUSSION}

Animal models have shown that exercise leads to an increased calcium level in brain, which might be associated with altered brain functions such as mood etc. (Denetsu, 1996). Figure. 1 shows noticeable changes in moods of male users. Majority of PEDs' users have observed changes in their mood ever since they started taking PEDs. The reported changes included sudden mood swings, mood fluctuations mainly. All of the users believe that they did not have those mood-related issues before. Of steroids users' majority of users of steroids together with erythropoietin reported noticing such changes. All the individuals using creatine alone also shared similar experience. And so did individuals using protein supplements with zinc. Among all these, the creatine users were found to be most significantly affected.

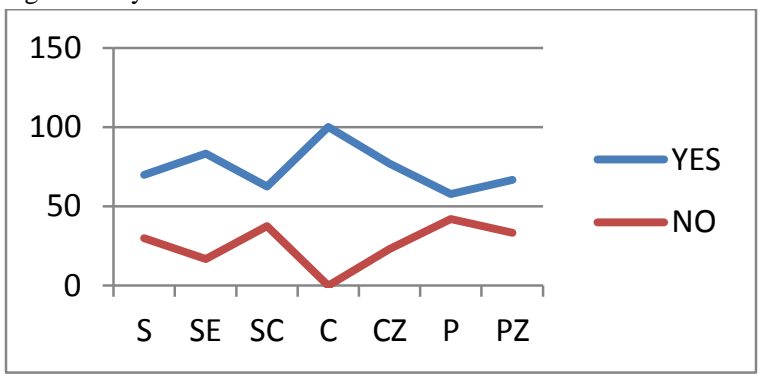

Figure 1. Noticeable changes in moods

Hassmén, (2000) reported how regular exercise could result in less anger and depression in the exercising individual. However, the findings of present study as shown in Figure. 2 accounts for individuals who workout and use PED as well, came up with the findings otherwise. Increased testosterone levels in the blood are associated with masculine behavior, aggressiveness and increased sexual desire, whereas an aggressive attitude is required for boosting athletic performance in gym it may result in unnecessary violence outside the gym as well (Kuipers, 1998). All the users of steroid with erythropoietin and those using creatine alone too reported increase in aggression level. Individuals of group $\mathrm{S}$ and group PZ showed a similar increment in aggression, while majority of group $\mathrm{CZ}$ also showed this tendency. On the other hand more than half of 
individuals of groups SC and P claimed to be more aggressive now as compared to when they did not take supplements. This aggressive attitude probably has something to do with the way one perceives image of his body, since, irrespective of the PED used, individuals who were physically stronger reported more aggression than those who were not physically that strong. Group $\mathrm{C}$ again was found to be overtly affected, together with users of steroid and erythropoietin combination.

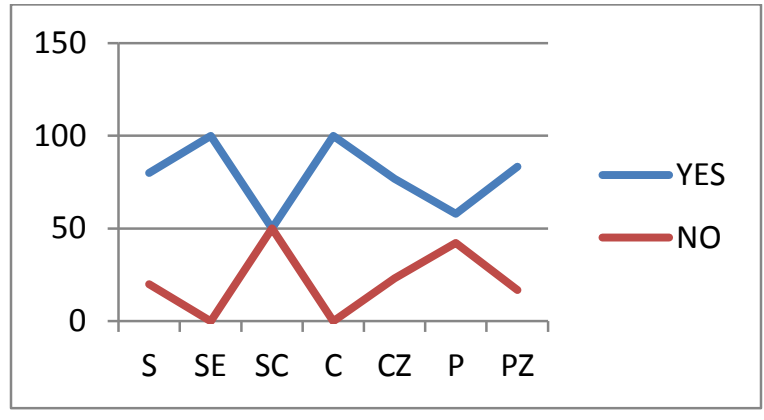

Figure 2. An increase in aggression

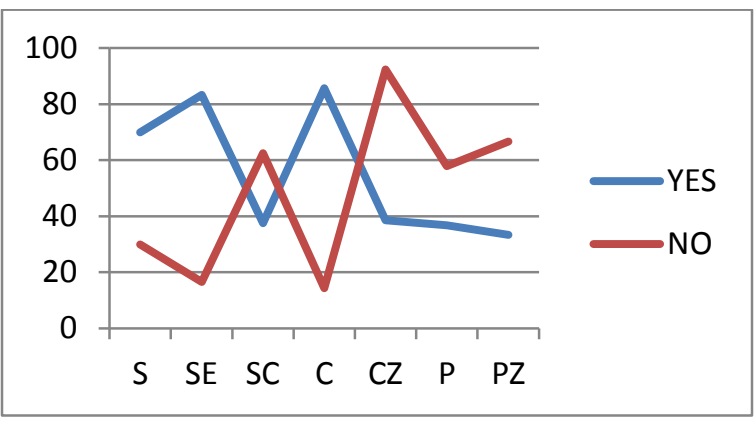

Figure 3. Noticeable changes in behavior

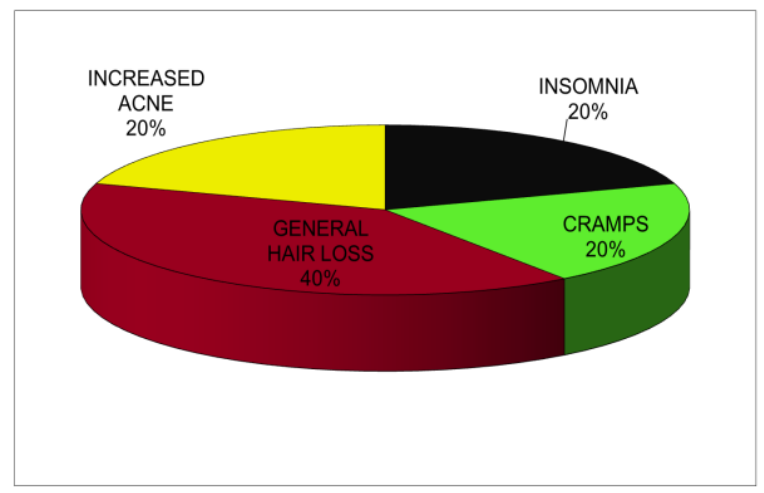

Figure 4. Reported side effects in steroids users (group S)

Due to decreased plasma glucose psychological processes that demand a conscious mental effort like self-control or decisionmaking gets impaired (Fairclough, 2004), which might be attributed to the findings presented in the study. Figure. 3 depicts that majority of individuals in Groups S, SE and C reported noticing behavioral changes. While majority of individuals of groups SC, CZ, P and PZ reported not noticing any behavioral changes since they started taking their respective PED. The most common behavioral changes reported in all the groups were similar. These ranged from anxiety

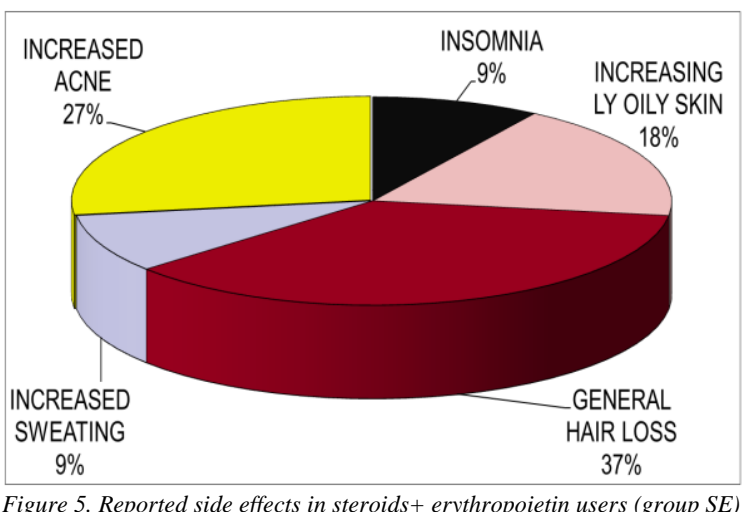

in users (group $S E$ )

to vivid imaginations, difficulty in adjusting in the same age group to clumsy attitude, from extremist attitude to negative thoughts.

In both genders hairloss, acne, sebaceous gland hypetrophy is reported upon using steroids (Kuipers, 1998). Hyperresponsivness and hyperproliferation of sebocytes as well as follicular keratinocytes can be attributed to androgen stimulation, which itself is the reason behind acne vulgaris (Thiboutot 1995; Thiboutot 1998). Increased acne was also a major finding in this group as shown in Figure. 4. The affected parts were not just face, but also neck and chest. Majority of the individuals using steroids alone had observed the side effects in the form of general hair loss. Androgen paradox is the phrase given to male pattern hair loss where androgen promotes hair growth on face suppressing it on temples and scalp vertex (Inui, 2012). The reported hair loss ranged from severe hair loss to hair thinning, from balding to general body hair thinning/loss

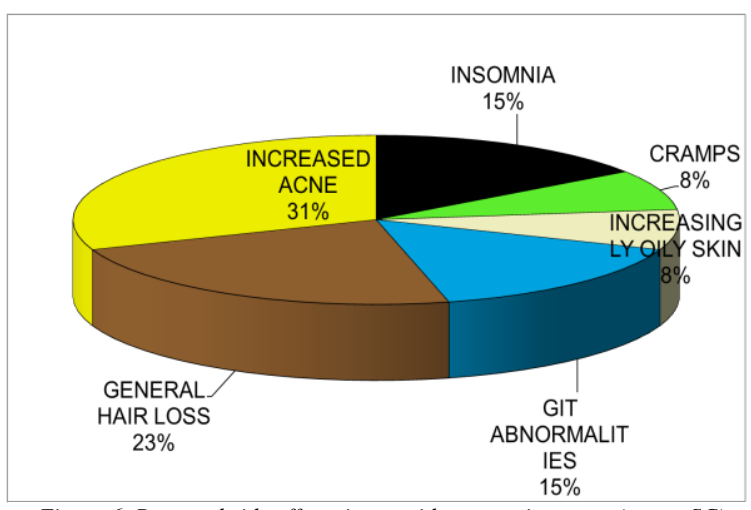

Figure 6. Reported side effects in steroids + creatine users (group SC)

which can be attributed to increased steroids in body. Many individuals also reported insomnia and non-restful sleep, especially on the day of loading dozes. Arvary (2000) reported how majority of cases admitted to a private treatment center for recouping with opioids addiction had abused these to counteract the insomnia and irritability caused by steroidal usage. Youqi (2004) suggested that athletes suffer from increased sleep onset latency due which leads to exercise induced insomnia. Muscle cramps was also common in group S, this might be due to overtraining or overstraining of muscles. Figure 5. shows that most of the individuals using steroids in combination with erythropoietin were also suffering from general hair loss and hair thinning. Increased facial acne was also very common, together with sparse acne on neck and chest in some individuals. This was reported together with an increasingly oily skin, which added to the acne problem. Some individuals claimed 
that they did not have oily skin before using the PEDs. The individuals of group SE also reported insomnia and improper sleeping habits. Some individuals, who claimed that since the use of PED they perspire even at room temperature with minimal physical activity, and so increased sweating problem was also reported. Users of steroids with creatine reported results that are shown in Figure.6, where increased acne followed by general hair loss were major findings. The occurrence of acne problem in majority of the users can be accounted for by the combinational usage of steroids and creatine supplements. Insomnia and non-restful sleeping habits were also reported in this group. Increasingly oily skin as well as muscle cramps were also reported in group SC.

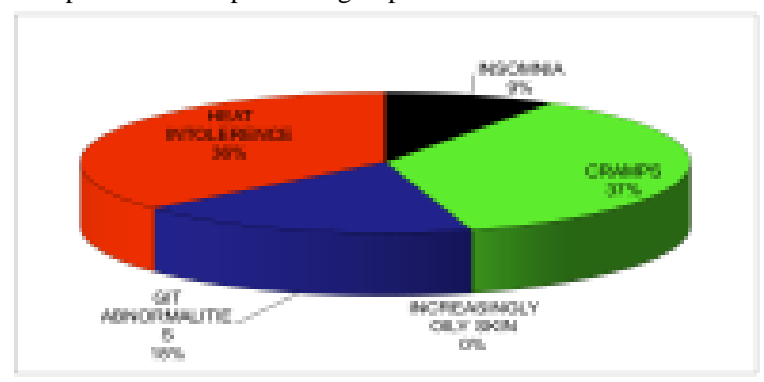

Figure 7. Reported side effects in creatine users (group C)

Figure. 7 show results of individuals using creatine supplements alone most commonly reported heat intolerance. Most of them claimed that they avoided going out in direct sunlight. They also

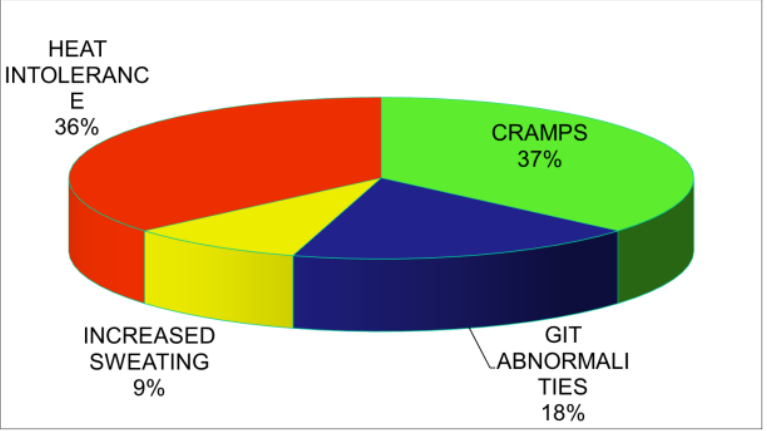

Figure 8. Reported side effects in creatine + zinc users (group CZ)

reported severe suntans. And they also suggested that in an environment where heat was unavoidable, they easily got frustrated, irritated and aggressive. They also suggested that heat intolerance drove them to train more ferociously during workout. An increased level of heat intolerance can be a result of underlying thyroid hormone abnormalities (Wilkins, 2007). A large majority also reported muscle cramps that maybe because of overstraining of muscles. Atheletes using cholesterol lowering drugs suffer from muscle cramps (Sinzinger, 2014). This hints that the users of this group and others who are suffering from muscle cramps might also be suffering from hypercholesterolemia. GIT abnormalities including nausea, indigestion, acidity and abdominal cramps were also reported. Insomnia was also a finding in this group C. Heat intolerance together with muscle cramps continues to be a common finding in majority of the users of creatine supplements in all combinations. The individuals using creatine with zinc claimed having heat intolerance problems also shared similar effects of heat intolerance on their mind and body as shown in Figure. 8 which are in line with those reported by individuals of group $\mathrm{C}$ previously. Together with heat intolerance, increased sweating was also a

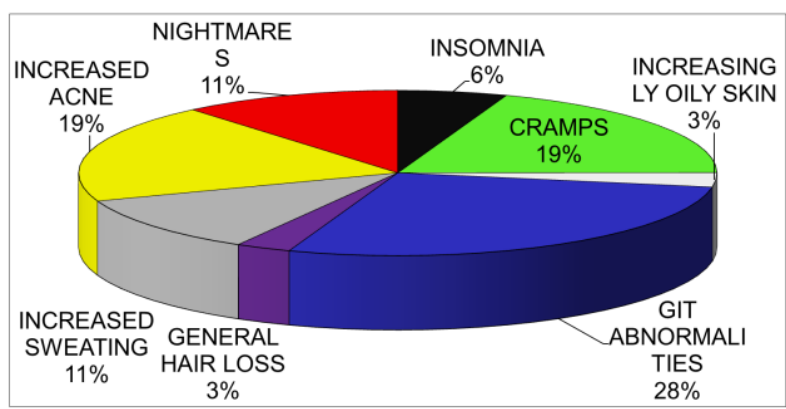

Figure 9. Reported side effects in group $P$

common characteristic in this group. Apart from these, GIT abnormalities were also found quite commonly in this group, which further cements the idea that creatine supplements have a tendency of disturbing the normal digestive system physiology. Users of protein supplements are asked to include more than usual carbohydrates in diet. Increased intake of refined carbohydrates has been linked with worsening acne (Mahmood, 2014). Figure. 9 depicts what individuals using protein supplements. GIT abnormalities were most commonly reported. Frequent indigestion, oral ulcers, acidity, abdominal cramps and nausea were reported by each one of these facing GIT abnormalities. Muscle cramps were also a common finding, most probably because of intense weight training. Increased acne problem was also reported commonly, where acne were limited to face only. This acne problem was also further worsened by increasingly oily skin, as reported by some individuals. Many individuals in this group also claimed increased sweating. Some of them also reported general hair loss, which was way less severe than steroids users. Moreover, hair loss did not seem to be a common factor in majority of the individuals, those who reported it may have a genetic predisposition to balding and hair loss. An eyebrow-raising finding was the frequent occurrence of nightmares in many individuals. An increased metabolism together with increased brain activity due to high energy diet has a potential to trigger nightmares (Stephen, 2007). These changes can be attributed to constantly high protein rich dietary supplements, which normally our body is not used to handling.

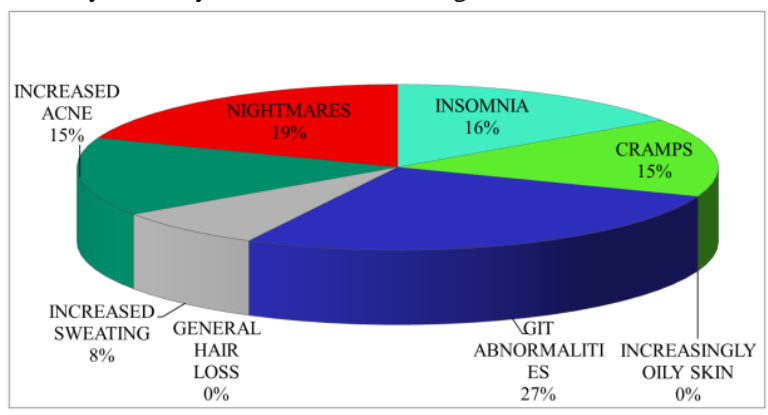

Figure 10. Reported side effects in group PZ

The side effects reported by individuals using protein supplements together with zinc are shown in Figure. 10, these were of similar pattern as reported by protein users. A large majority shared facing same GIT abnormalities as reported by individuals using protein supplements only. Frequent nightmares were also a common feature in this group too, which further pillars the idea that constantly high amount of protein in blood has got the activation of specific pathways in brain that lead to the frequent occurrence of nightmares. Insomnia was also commonly reported. Nightmares affect sleep 
pattern and it has been linked with nocturnal awakenings as well as difficulty in falling back asleep (Simor, 2014). The users of protein and zinc combination supplements appear to be suffering from the same. They also reported an increased incidence of facial acne in collaboration with increasing tendency to break into a sweat even a room temperature, with minimal of physical activity. Muscle cramps were also commonly reported in group protein plus zinc combination users owing to over-training of skeletal muscles.

\section{CONCLUSION}

The present study outlines that PED usage exert there effects on mind, body and personality of the users. Where mood swings and increase in aggression were reported by users of all PED included in the study, former was mostly reported by creatine users mainly the latter being most common in steroids-eryhtropoietin as well as creatine users. A mixed response was given for changes in behavior by all PED users, indicating variables other than PED being responsible for the reported changes. Apart from these insomnia and frequent nightmares suggest influence of PED on mind of users. Changes reported on body by users ranged from excess sweating, heat intolerance, increasingly oily skin, frequent acne breakouts, male pattern alopecia, muscle cramps and GIT abnormalities. Findings of this study throw light on the fact that when PED usage ensures a muscled physique it also triggers certain influences on the users which in turn raise a question, is attaining a beefy physique fair enough to trade for one's original physiologically balanced mind, personality and body? This question must be answered by gym going individual himself before letting the drug enter the circulatory system.

\section{REFERENCES:}

- Arvary, D., Pope, HG., J.r. (2000). Anabolic-androgenic steroids as a gateway to opioid dependence. New Engl. J. Med. 342:1532

- $\quad$ Colt EWD, Wardlaw SL, Frantz, A.G. (1981). The effect of running on plasma B-endorphin. Life Sci 25:1637-1640.

- D. M. W. de Coverley Veale (1987). Exercise and mental health Acta psychiatr Academic Department of Psychiatry, The Royal Free hospital, London, United Kingdom.. scand. 76:113-120.

- $\quad$ Denetsu, S., \& Kayo, A.K. (1996). The mechanism by which exercise modifies brain function Physiology \& Behavior 60(1) 177-181.

- $\quad$ Fairclough, S.T. \& Houston, K. (2004). "A metabolic measure of mental effort", Biol. Psychol. 66 (2): 177-90, doi:10.1016/j.biopsycho.2003.10.001, PMID 15041139

- Henning, B., Till, S., Mary, E., Spilker, Gjermund, H., Marcus, K., Klaus, J., Wagner., Michael, V., Achim, B., \& Thomas, R. T. (1998). The Runner's High: Opioidergic Mechanisms in the Human Brain. Cereberal Cortex doi:10.1093/cercor/bhn013

- Inui, S. \& Itami, S. (2012). "Androgen actions on the human hair follicle: Perspectives". Experimental Dermatology22 (3): 168-71. doi:10.1111/exd.12024

- Jason, J., Koch. (2002). Pediatrics in Review. American Academy of Pediatrics Southdale Pediatrics, Edina, MN 23:310-317.

- Kuipers, H. (1998). Anabolic steroids: side effects. In: Encyclopedia of Sports Medicine and Science, T.D.Fahey (Editor). Retrieved from Internet Society for Sport Science: http://sportsci.org. .
- $\quad$ Mahmood, SN; Bowe, WP. (2014). "Diet and acne update: carbohydrates emerge as the main culprit." Journal of drugs in dermatology: JDD 13 (4): 428-35. PMID 24719062

- $\quad$ Mirza F \& Ahmed S (2013). Psychological effects of using Power-enhancing drugs on Gym-exercising individuals. Int J Pharm Sci Res 4(4); 1565-1568.

- $\quad$ Peter, H., Nathalie, Koivula., A. U. (2000). Physical Exercise and Psychological Well-Being: A Population Study in Finland Preventive Medicine 30(1) 1725doi:10.1006/pmed.1999.0597.

- $\quad$ Sime, W.E. (1987). Exercise in the prevention and treatment of depression. In Exercise and Mental Health (Edited by WP MORGAN and SE GOLDSTON). Washington DC: Hemisphere Publishing Corp.

- Simor, P., Horváth, K., Gombos, F., Takács, K. P., \& Bódizs, R. (2012). Disturbed dreaming and sleep quality: altered sleep architecture in subjects with frequent nightmares. European archives of psychiatry and clinical neuroscience, 262(8), 687696.

- $\quad$ Sinzinger, H., \& O'Grady, J. (2004). Professional athletes suffering from familial hypercholesterolaemia rarely tolerate statin treatment because of muscular problems. British journal of clinical pharmacology, 57(4), 525-528.

- Stephen, L., (2006). "Nightmares". Retrieved from http://www.psychologytoday.com/conditions/nightmares.

- $\quad$ Thiboutot, D., Harris, G., Iles, V., Cimis, G., Gilliland, K., \& Hagari, S. (1995). Activity of the Type 1 5\&agr;-Reductase Exhibits Regional Differences in Isolated Sebaceous Glands and Whole Skin. Journal of investigative dermatology, 105(2), 209-214.

- Thiboutot, D., Knaggs, H., Gilliland, K., \& Lin, G. (1998) Activity of 5- $\alpha$-reductase and 17- $\beta$-hydroxysteroid dehydrogenase in the infrainfundibulum of subjects with and without acne vulgaris. Dermatology 196:38-42

- Wilkins., \& Lippincott., W. (2007). Interpreting signs \& symptoms. Lippincott Williams \& Wilkins; ISBN 9781582556680. p. 306-307.

- Youqi, S., Zhihong, Z., Ke, N., Jianhong, L. A. (2004). PreOlympic Congress The epidemiological survey of exerciseinduced insomnia in chinese athletes. Retrieved from http://cev.org.br/biblioteca/the-epidemiological-survey-ofexercise-induced-insomnia-in-chinese-athletes 